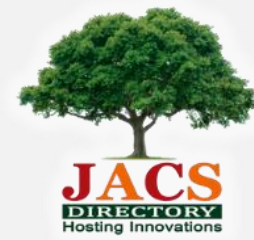

Journal of Nanoscience and Technology

\title{
Synthesis and Characterization of Mg Doped ZnO and Importance of Secondary Phases
}

\author{
V. Saraswathi1,*, R. Ramasamy², R. Ramanathan ${ }^{3}$ \\ ${ }^{1}$ Saranathan College of Engineering, Trichy - 620 012, Tamilnadu, India. \\ ${ }^{2}$ P.G.\& Research Department of Physics, National College (Autonomous), Trichy - 620 001, Tamilnadu, India. \\ ${ }^{3}$ Department of Physics, Government Arts College, Kulithalai - 639 120, Tamilnadu, India.
}

\section{A R T I C L E D E T A I L S}

\section{Article history:}

Received 20 May 2019

Accepted 08 June 2019

Available online 12 June 2019

Keywords:

Nitriding Method

Mg Doped ZnO

PL Analysis

\begin{abstract}
A B S T R A C T
Magnesium (Mg) doped zinc oxide $(\mathrm{ZnO})$ is synthesized by nitriding method at $300{ }^{\circ} \mathrm{C}$. XRD studies shows that crystallite size at $300{ }^{\circ} \mathrm{C}$ is $27.3 \mathrm{~nm}$. The secondary phase shows the disruption of the hexagonal structure of the $\mathrm{ZnO}$. EDAX confirms the presence of $\mathrm{Zn}, \mathrm{Mg}$ and 0 and hence the sample is pure. FTIR studies confirm the presence of $\mathrm{ZnO}$ and $\mathrm{MgO}$. Optoelectronic studies are also conducted and it has been confirmed that due to the doping of $\mathrm{Mg}$ and also which is present in secondary phase, the PL spectra shows a broad red shift from $633 \mathrm{~nm}$ to $651 \mathrm{~nm}$, which shows the significance of the secondary phases.
\end{abstract}

\section{Introduction}

Zinc Oxide is a semiconducting material which has interesting characteristics and device applications [1]. There are various synthesis methods to grow different $\mathrm{ZnO}$ nanostructures, including nanoparticles, nanowires, nanorods, nanotubes, nanobelts, and other complex morphologies [2]. Many methods have been used to prepare Zno nano particles like sol-gel method [3], thermal decomposition, and chemical vapor deposition and alloy evaporation deposition methods. The physical chemical properties and the applications of the $\mathrm{ZnO}$ are altered by the ration of the doping elements [4]. It also depends on the preparation method and condition. Thus, the $\mathrm{ZnO}$ is doped with elements ( $\mathrm{Al}, \mathrm{Ga}, \mathrm{In}$, $\mathrm{Cu}, \mathrm{Mg}$ and so on) to increase electrical conductivity and transmittance in the visible range and stability against heat [5]. Thus, magnesium oxides act as the dopant, and enter into $\mathrm{ZnO}$ lattices [6] and disrupt the local symmetry of $\mathrm{ZnO}$ structure while the divalent magnesium ions ( $\mathrm{Mg}^{2+}$ ions) of wide energy band gap of $7.80 \mathrm{eV}$ [7] take the interstitial positions around $\mathrm{Zn}^{2+}$ ions in the precipitation. As a magnesium is an alkaline earth metal, it is devoid of limited to a small area d levels, the complications with optical properties arising from the electronic structures much straighten out, and the alloy consequently provides a better scope to enhance the band gap of wurtzite $\mathrm{ZnO}$ [8]. The main advantages of this semiconductor are, it can be grown at even low temperature [9], wide direct band-gap energy (3.37 eV) [10] and large exciton binding energy (60 meV) [11]. Due to this, it is important to make it attractive for high temperature electronic and optoelectronic application, for example, light emitting diodes (LEDs), UV detectors, and semiconductor laser [12], field emission material, gas sensor and transparent conductive coatings. Nowadays, $\mathrm{ZnO}$ is one of the materials that have been used in forensic field for fingerprint detection [13]. The electromagnetic radiation wave-length of $\mathrm{ZnO}$ nanoparticles is about $290 \mathrm{~nm}$ and its photoluminescence property emit green and orange light in visible region at $520 \mathrm{~nm}$ and $620 \mathrm{~nm}$, respectively. Due to these visible emissions, $\mathrm{ZnO}$ nanoparticle is attractive in fingerprint application, where it is needed to form images on dark surfaces by means of UV excitation [14]. Doping is known to modify the, electrical and optical properties of metal oxides. It has been successfully used to modify energy band gap, improve electron transfer and so affect the optical properties of $\mathrm{ZnO}$ that involved its three major luminescence that are ultraviolet (UV) green and red emissions.

\section{Experimental Methods}

\subsection{Materials}

Zinc nitrate, magnesium nitrate, citric acid, urea, and poly ethanol glycol (Nice Company AR Grade) were purchased and used without further purification.

\subsection{Experimental Sections}

$60 \mathrm{~g}$ of zinc nitrate was dissolved in a $75 \mathrm{~mL}$ of double distilled water which was mixed with $60 \mathrm{~g}$ of citric acid (dissolved in $10 \mathrm{~mL}$ water) and $60 \mathrm{~g}$ of urea (dissolved in $10 \mathrm{~mL}$ of water) and kept in a magnetic stirrer for $10 \mathrm{~min}$. After 10 minutes, $5 \mathrm{~g}$ of magnesium nitrate was taken and dissolved in $10 \mathrm{~mL}$ of water which was mixed with a zinc nitrate solution. This event was kept in a magnetic stirrer for one hour at a temperature of $80{ }^{\circ} \mathrm{C}$. Then, $10 \mathrm{~mL}$ PEG (poly ethylene glycol) was added and again kept in the hot plate for 10 hours at a constant temperature. Later it was kept in muffle furnace for $300{ }^{\circ} \mathrm{C}$ of temperatures up to $3 \mathrm{~h}$.

\subsection{Instrumental Used}

The synthesized material was characterized using the instruments XRD of Scanning Mode 2 Theta/Theta of scanning type continuous scanning XRay $40 \mathrm{kV} / 30 \mathrm{~mA}$ and the data was recorded using $\mathrm{CuK} \beta$ radiation. JEOL JSM 6510-LV scanning electron microscope with MOXTEK 550i thin film coated IXRF energy dispersive spectrometer (EDAX) was used for morphological and for determining the percentage of elements present in the sample. The photo luminescence studies were done using LS 45 fluorescence spectrometer by PerkinElmer model. Reflection and transmission studies were done using JASCO UV-Vis DRS photometric mode V - 650 series model. The band gap of the material was studied using UV Spectrum-JASCO V-650 series of Kubelka-Munk model.

\section{Results and Discussion}

\subsection{X-Ray Diffraction Analysis}

X-ray diffraction (XRD) analysis is used to investigate the crystal structure of the sample. Fig. 1 represents the XRD pattern of Mg doped $\mathrm{ZnO}$. The intensity data was collected over a $2 \theta$ range of $10-80^{\circ}$. This XRD pattern has the characteristic peaks of $\mathrm{ZnO}$ [15]. The average crystallite size and the various XRD parameters for the maximum peak intensity [101] are tabulated in Tables 1 and 2. Table 2 shows the grain size and the FWHM which are calculated for all the peaks of XRD spectra. The grain size 
(D) is obtained from XRD peaks using the Debye- Scherrer's equation [16], $D=(K \lambda / \beta \cos \theta)$, where $K$ is Dimensionless shape factor, with a value close to unity. The shape factor has a typical value of about 0.9 , but varies with the actual shape of the crystallite; $\lambda=$ Sources for CuK $\alpha=1.541^{*} 10^{-10}$, $\beta=$ Full Width Half Maximum value XRD data and $\theta=$ Bragg's Angle (Corresponding $2 \theta$ Values are converted into $\theta$ values)

The microstrain can be calculated from The dislocation density of the nanoparticle is

The d-spacing of the atom is calculated by

$$
\begin{aligned}
& \varepsilon=\beta \operatorname{Cos} \theta / 4 \\
& \mathrm{~S}=1 / \mathrm{D}^{2}(\mathrm{~nm})^{-2} \\
& \mathrm{~d}=(\mathrm{n} \lambda / \operatorname{Sin} \theta) \AA
\end{aligned}
$$

where $\mathrm{n}=$ order of diffraction, $\lambda=$ Wavelength and $\theta=$ diffraction angle.

Table 1 XRD parameters of synthesized $\mathrm{ZnO}$ at temp $300^{\circ} \mathrm{C}$

\begin{tabular}{lll}
\hline S.No. & XRD Parameters & Plane [101] \\
\hline 1 & Grain Size (D) & $27.3 \mathrm{~nm}$ \\
2 & Micro Strain $(\varepsilon)$ & 0.005106 \\
3 & Dislocation density $(\mathrm{S})$ & $13.3^{*} 10^{14}(\mathrm{~nm})^{-2}$ \\
4 & d-spacing & $2.395^{*} 10^{-10} \mathrm{~m}$ \\
5 & FWHM $(\beta)$ & 0.3762 \\
\hline
\end{tabular}

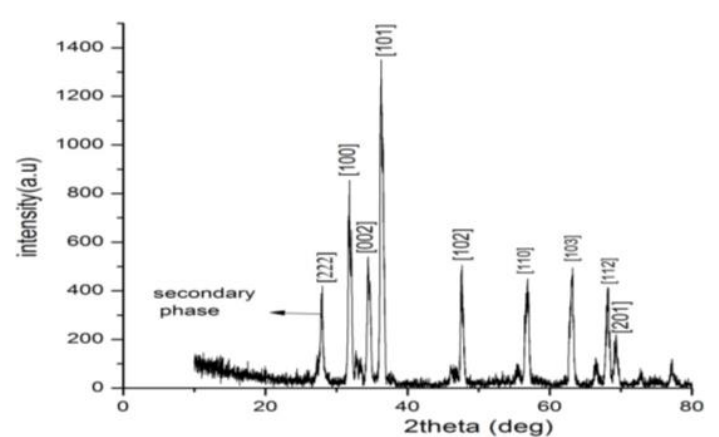

Fig. 1 XRD pattern of synthesized $\mathrm{ZnO}$ at temp $300{ }^{\circ} \mathrm{C}$

$2 \theta$ values $31.89^{\circ}, 34.73^{\circ}, 36.29^{\circ}, 47.64^{\circ}$ are observed which corresponds to [100], [002], [101], [102] planes, shows a typical XRD pattern of ZnO particles [17]. This XRD peak matches with the JCPDS card no. 36-1451 of the $\mathrm{ZnO}$ structure which are standard hexagonal peaks and no, secondary phase is within the limit of the XRD measurement and apparently there is no peak for MgO. Therefore, the XRD peaks indicating Mg ions are substituted for $\mathrm{Zn}$ ions because both have very similar ionic radii $(0.57$ and $0.60 \AA$ ) [18], and there is no variation in the structure of the $\mathrm{ZnO}$ nanoparticles. But there is a secondary phase at about $28^{\circ}$ which corresponds to [222] [19] which may be due to $\mathrm{MgO}$ which has orthorhombic spaces which disrupts the wurtzite hexagonal structure with a doping amount of $3.5 \mathrm{~mol} \%$ of $\mathrm{mg}$ doped $\mathrm{ZnO}$. Hence, these result demonstrate the fact that $\mathrm{Mg}$-doped $\mathrm{ZnO}$ synthesized at $300^{\circ} \mathrm{C}$ contains amorphous $\mathrm{Mg}(\mathrm{OH})_{2}$, and at high temperature (above $\left.300{ }^{\circ} \mathrm{C}\right) \mathrm{Mg}(\mathrm{OH})_{2}$ decomposes [20] and leads to $\mathrm{Mg}^{2+}$ diffusion into the $\mathrm{ZnO}$ lattice structure. Thus, this indicates that $\mathrm{Mg}^{2+}$ is not incorporated into the $\mathrm{ZnO}$ lattice, which forms a secondary phase. This confirms that Mg disrupts and occupies the Zn site [21].

Table 2 The grain size and the FWHM for the planes of XRD spectra

\begin{tabular}{lllll}
\hline S.No & Planes & $2 \theta\left(^{\circ}\right)$ & $\beta$ & Grain size (D) $\mathrm{nm}$ \\
\hline 1 & {$[222]$} & 28.36 & 0.269 & 31.82 \\
2 & {$[100]$} & 31.89 & 0.33 & 26.16 \\
3 & {$[002]$} & 34.73 & 0.356 & 24.41 \\
4 & {$[102]$} & 47.64 & 0.494 & 18.37 \\
5 & {$[110]$} & 57 & 0.59 & 16.01 \\
6 & {$[103]$} & 62.34 & 0.646 & 15.02 \\
7 & {$[112]$} & 68.28 & 0.708 & 14.17 \\
8 & {$[201]$} & 69.32 & 0.704 & 14.04 \\
\hline
\end{tabular}

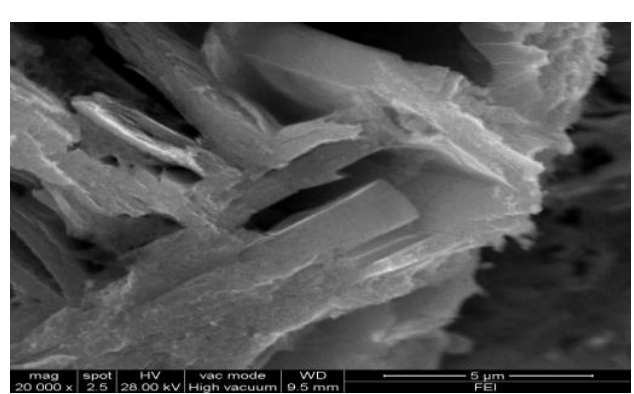

Fig. 2 SEM pattern of synthesised $\mathrm{ZnO}$ at temp $300^{\circ} \mathrm{C}$ https://doi.org/10.30799/jnst.255.19050406

\subsection{Scanning Electron Microscopy Analysis}

The morphology of Mg doped $\mathrm{ZnO}$, from scanning electron microscopy (SEM) shown in Fig. 2, shows irregular flakes, which are not in nanosized though the crystallite size falls under nanoregion, from XRD analysis.

\subsection{Energy Dispersive X-Ray Analysis}

The energy dispersive X-ray (EDAX) graph is shown in Fig. 3. The EDAX analysis shows peaks of $\mathrm{Zn}, \mathrm{Mg}$ and $\mathrm{O}$ elements with no additional peaks. This confirms that the sample is pure. The percentage of $\mathrm{Zn}, \mathrm{Mg}$ and $\mathrm{O}$ elements present are tabulated in Table 3 .

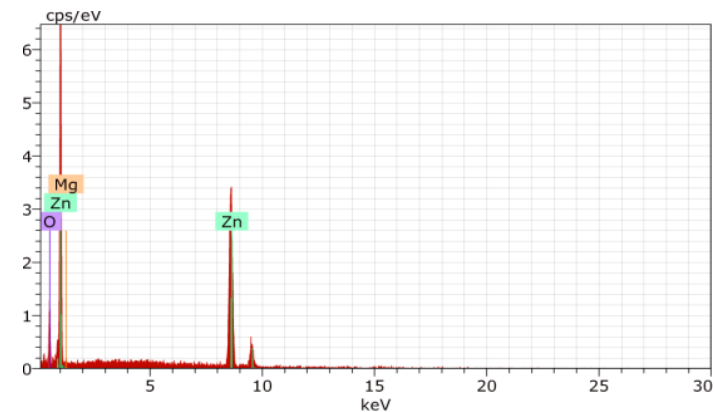

Fig. 3 EDAX pattern at $300{ }^{\circ} \mathrm{C}$

Table 3 The atomic percentage calculated for synthesized $\mathrm{ZnO}$ at $300{ }^{\circ} \mathrm{C}$

\begin{tabular}{ll}
\hline Element & Atomic $\% 300^{\circ} \mathrm{C}$ \\
\hline $\mathrm{Zn}$ & 41.13 \\
$\mathrm{O}$ & 54.95 \\
$\mathrm{Mg}$ & 3.92 \\
\hline
\end{tabular}

\subsection{Fourier Transform Infrared Spectroscopy Analysis}

Fourier transform infrared spectroscopy (FTIR) analysis is done for the sample. Fig. 4 shows the FTIR spectrum of synthesized $\mathrm{ZnO}$ at $300{ }^{\circ} \mathrm{C}$. The various modes of vibration are observed at different regions of FTIR spectrum. The broad peak at $3395.88 \mathrm{~cm}^{-1}$ [22] indicated the $-\mathrm{OH}$ stretching vibrations. These stretching vibrations correspond to hydroxyl band. The peak at $1515.78 \mathrm{~cm}^{-1}$ [23] is due to bending vibration of free water. This vibration indicates the presence of bound $\mathrm{H}_{2} \mathrm{O}$ on the surface of the sample. The absorption at $830.20 \mathrm{~cm}^{-1}$ [24] is due to the stretching vibration of Mg-O-Mg bonding. The presence of peaks at $445.7 \mathrm{~cm}^{-1}$ [25] is the characteristic peaks of $\mathrm{Zn}-\mathrm{O}$ stretching vibration. It is in the lower frequency side is due to some structural changes by doping with $\mathrm{Mg}$ [26].

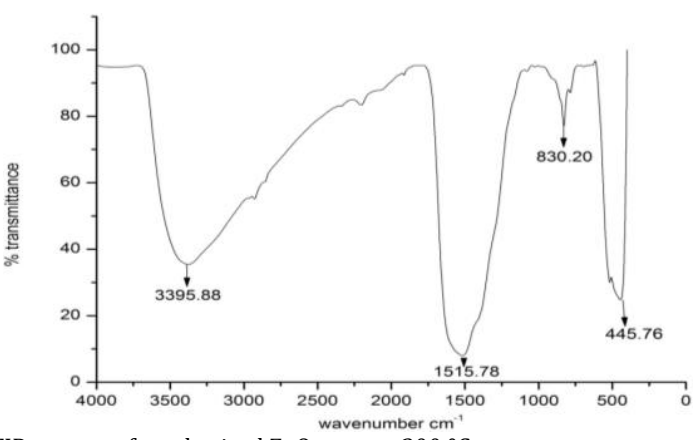

Fig. 4 FTIR pattern of synthesized $\mathrm{ZnO}$ at temp $300^{\circ} \mathrm{C}$

Table 4 FTIR peak interpretation

\begin{tabular}{ll}
\hline Wave number $\left(\mathrm{cm}^{-1}\right)$ & Assignment \\
\hline $3395.88(\mathrm{~m})$ & O-H stretching \\
$1515.78(\mathrm{~s})$ & Bound $\mathrm{H}_{2} \mathrm{O}$ \\
$830.20(\mathrm{~m})$ & Mg-O stretching \\
$445.76(\mathrm{~s})$ & Zn-O stretching \\
\hline
\end{tabular}

\subsection{UV-Diffuse Reflectance Spectra}

In order to investigate the doping effect on optical properties, the UVVis diffuse reflectance spectra has been observed of synthesized $\mathrm{ZnO}$ in Fig 5 and the band gap of the sample is calculated. Fig. 5b represents the transmittance spectra of synthesized $\mathrm{ZnO}$ in the wavelength range of 200$1000 \mathrm{~nm}$. The reflectance edge is $313 \mathrm{~nm}$ for the temperature $300{ }^{\circ} \mathrm{C}$. In the spectra gradually the reflectance shifted towards the green band emission and hence it indicates the incorporation of magnesium in the zinc oxide interstitial site. This confirms that the material has a good reflectance characteristic. The sample show that the reflectance is 
increasing from UV to visible range with more than $80 \%$ of reflectance. Equally in the transmittance spectrum the spectrum shows the same character [27]
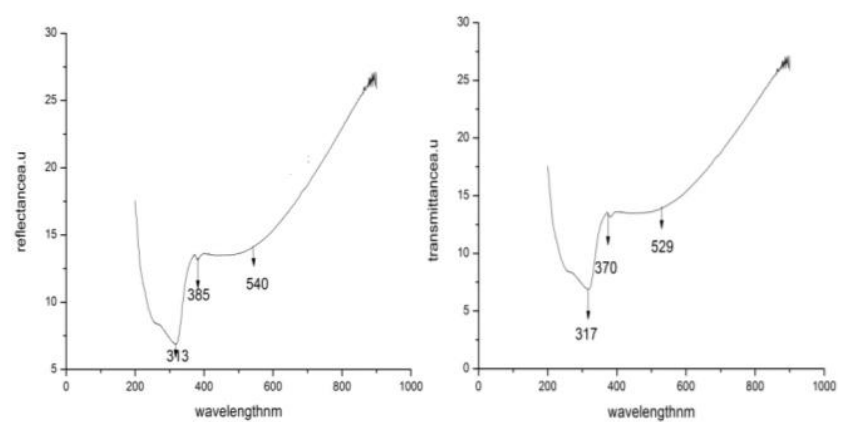

Fig. 5 UV-Vis DRS spectra for Reflectance and b) transmittance

\subsection{Band Gap Energy}

The bandgap energy calculation of $\mathrm{ZnO}$ material was performed based on the diffuse reflectance spectra by using Kubelka Munk plot [28] shown in the Fig. 6. The optical band gap has been calculated and found to increase from $3.18 \mathrm{eV}$ for undoped $\mathrm{ZnO}$ [29] to $3.44 \mathrm{eV}$ for Mg-doped $\mathrm{ZnO}$ at temp $300{ }^{\circ} \mathrm{C}$, because $\mathrm{MgO}$ has a wider band gap than $\mathrm{ZnO}$ [30]. Hsu et $a l$. reported that doping with $\mathrm{Mg}$ increases the band gap of $\mathrm{ZnO}$. This increase in the band gap might be due to increase in carrier concentration that blocks the lowest states in the conduction band, this effect is known as Burstein-Moss effect. Excitonic transition energy shifted to a high energy value due to $\mathrm{Mg}$ doping in $\mathrm{ZnO}$. During the formation of the $\mathrm{Mg}: \mathrm{ZnO}$ structure, $\mathrm{Mg}^{2+}$ ions were substituted for the $\mathrm{Zn}^{2+}$ ions. However, $\mathrm{Mg}$ doping in the $\mathrm{ZnO}$ acts as donor and the band gap of the structure increases.

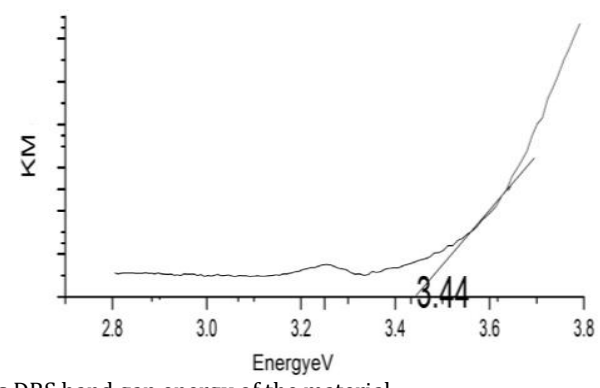

Fig. 6 UV-Vis DRS band gap energy of the material

\subsection{Photo Luminescence}

The photoluminescence spectra of synthesized Zinc oxide recorded with the excited wavelength of $651 \mathrm{~nm}$ shown in the Fig. 7. For the temperature $300{ }^{\circ} \mathrm{C}$, two distinct emission features can easily be discerned: One around $371 \mathrm{~nm}$ of $3.34 \mathrm{eV}$ and the other at $651 \mathrm{~nm}$ of 1.9 $\mathrm{eV}$. The fluorescence at $371 \mathrm{~nm}$ corresponds to the characteristic band edge emission. The red luminescence at $651 \mathrm{~nm}$ observed in the present case has been assigned to electronic transitions from the $\mathrm{Zn} i$ level to the valence band. The energy level corresponding to $\mathrm{Zn}$ interstitials lies just below the conduction band, and it can trap photo excited electrons followed by their radiative recombination with holes in the valence band. In our experiment, an interesting phenomenon is observed that the intensity of the visible emission band in $\mathrm{Mg}$-doped $\mathrm{ZnO}$ is stronger. This may be attributed to the increase in concentration of oxygen vacancies and surface recombination effects on the material [31]. Mg doped $\mathrm{ZnO}$ structures have changed the optical properties significantly.

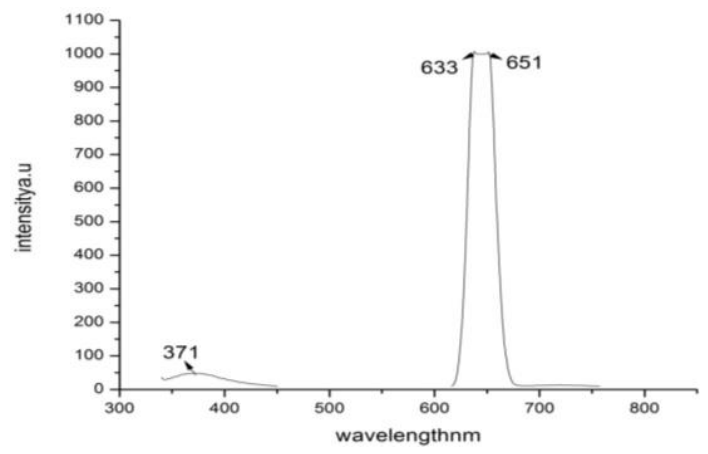

Fig. 7 Photo luminescence for temp $300{ }^{\circ} \mathrm{C}$
Mg doped $\mathrm{ZnO}$ is synthesized and its structural and optical properties are investigated. EDAX confirms the purity of the sample and the average crystallite size is $27.3 \mathrm{~nm}$ at $300{ }^{\circ} \mathrm{C}$, from XRD analysis. The morphology from the SEM image shows irregular sheets are formed which are above the nanoscale. The FTIR spectrum shows the presence of $\mathrm{MgO}$ and $\mathrm{ZnO}$ in the sample. The photo luminescence studies reveal a strong emission at red band region which indicates the doping of $\mathrm{Mg}$ in the $\mathrm{ZnO}$ interstitial sites. UV-Vis DRS spectra show a good reflectance and transmittance characteristics. The optical band gap of the material is calculated as 3.44 $\mathrm{eV}$ at the temperature $300^{\circ} \mathrm{C}$. Hence, from this it is seen that the size of the particles are greater than the nanoscale, but with crystallite size in the nanoscale, the presence of $\mathrm{Mg}$ as a dopant has disrupted the hexagonal structure, which is shown by the secondary phase from XRD spectra and the presence of $\mathrm{MgO}$ dopant has modified the energy levels and the band gap energy of $\mathrm{ZnO}$. Further, this proves the importance of secondary phases which is established from the PL studies, with broad red shift from $633 \mathrm{~nm}$ to $651 \mathrm{~nm}$ which makes the material more significant for the optoelectronic applications.

\section{References}

[1] S. Baruha, J. Dutta, Hydrothermal growth of $\mathrm{ZnO}$ nanostructure, Sci. Technol Adv. Mater. 10 (2009) 013001:1-18.

[2] R.M. Marcos, S.V. Daniel, M.N. Antonio, Zinc oxide composites prepared by in situ process: UV barrier and luminescence properties, Mater. Lett. 125 (2014) 75-77.

[3] S.P. Ranvir, Preparation of modified ZnO materials by sol-gel process and their characterization, Master of Technology, Thapar University, Punjab, India, 2009.

[4] K.I. Hagemark, Defect structure of Zn-doped ZnO, J. Solid State Chem. 16 (1976) 293-299.

[5] Rajkrishna Dutta, Nibir Mandal, Mg doping in wurtzite ZnO coupled with native point defects: a mechanism for enhanced n-type conductivity and photoluminescence, Appl. Phys. 101 (2012) 042106:1-4.

[6] M. Zamfirescu, A. Kavokin, B. Gil, G. Malpuech, M. Kaliteevski, ZnO as a material mostly adapted for the realization of room-temperature polariton lasers, Phys. Rev. B 195 (2002) 563-567.

[7] H.C. Hsu, C.Y. Wu, H.M. Cheng, W.F. Hsieh, Band gap engineering and stimulated emission of ZnMgO nanowires, Appl. Phys. Lett. 89 (2006) 013101:1-3.

[8] G. Xiong, U. Pal, J.G. Serrano, K.B. Ucer, R.T. Williams, Photoluminescence and FTIR study of $\mathrm{ZnO}$ nanoparticles: the impurity and defect perspective, Phys. Stat. Sol. 3(10) (2006) 3577-3581.

[9] G.C. Yi, C. Wang, W.I. Park, ZnO nanorods: Synthesis, characterization and applications, Semicond. Sci. Technol. 20 (2005) S22-S34.

[10] I. Polat, S. Yılmaz, E. Bacaksız, Y. Atasoy, M. Tomakin, Synthesis and fabrication of Mg-ZnO-based dye-synthesized solar cells, J. Mater. Sci. Mater. Electron. 25 (2014) 3173-3178.

[11] M. Eskandari, N. Haghighi, V. Ahmadi, F. Haghighi, S.H.R. Mohammadi, Growth and investigation of antifungal properties of $\mathrm{ZnO}$ nanorod arrays on the glass, Phys. B Cond. Matter 406(1) (2011) 112-114.

[12] J. Hassan, M. Mahdi, A. Ramizy, H.A. Hassan, Z. Hassan, Fabrication and characterization of $\mathrm{ZnO}$ nanorods/p-6H-SiC heterojunction LED by microwave-assisted chemical bath deposition, Superlattice Microstruct. 53 (2013) 31-38.

[13] M. Guzman, B. Flores, L. Malet, S. Godet, Synthesis and characterization of zinc oxide nanoparticles for application in the detection of fingerprints, Mater. Sci. Forum 916 (2018) 232-236.

[14] P. Taunk, R. Das, D. Bisen, R. Kumar Tamrakar, Structural characterization and photoluminescence properties of zinc oxide nano particles synthesized by chemical route method, J. Radiat. Res. Appl. Sci. 8 (2015) 433-438.

[15] L. Umaralikhan, M. Jamal Mohamed Jaffar, Green synthesis of $\mathrm{ZnO}$ and $\mathrm{Mg}$ doped $\mathrm{ZnO}$ nanoparticles, and its optical properties, J. Mater. Sci. Mater. Electron. 28 (2017) 7677-7685.

[16] R.M. Alwan, Q.A. Kadhim, K.M. Sahan, R.A. Ali, R.J. Mahdi, Synthesis of zinc oxide nanoparticles via sol-gel route and their characterization, Nanosci. Nanotechnol. 5 (2015) 1-6.

[17] Saber Farjami Shayesteh, Armin Ahmadi Dizgah, Effect of doping and annealing on the physical propertiesof ZnO:Mg nanoparticles, Pram. J. Phys. 81 (2013) 319-330.

[18] P. Maddahi, N. Shahtahmasebi, A. Kompany, M. Mashreghi, S. Safaee, F. Roozban, Effect of doping on structural and optical properties of $\mathrm{ZnO}$ nanoparticles: Study of antibacterial properties, Mater. Sci. Poland 32(2) (2014) 130-135.

[19] A.M. Limaa, M.R. Davolosa, C. Legnanib, W.G. Quirinob, M. Cremonab, Low voltage electroluminescence of terbium- and thulium-doped zinc oxide films, J. Alloys Compd. 418 (2006) 35-38.

[20] V. Etacheri, R. Roshan, V. Kumar, Mg-Doped ZnO nanoparticles for efficient sunlight-driven photocatalysis, ACS Appl. Mater. Interf. 4 (2012) 2717-2725.

[21] B.K. Sonawane, M.P. Bhole, D.S. Patil, Structural, optical and electrical properties of Post annealed $\mathrm{Mg}$ doped $\mathrm{ZnO}$ films for optoelectronics applications, Opt. Quant. Electron. 41 (2009) 17-26.

[22] I.S. Saputra, Y. Yulizar, Biosynthesis and characterization of $\mathrm{ZnO}$ nanoparticles using the aqueous leaf extract of Imperata cylindrica L, IOP Conf. Ser. Mater. Sci. Eng. 188 (2017) 012004:1-5.

\section{Conclusion}


[23] E. Bhawani, G.S. Harish, P. Sreedhara Reddy, Effect of Cu doping on electrical, photoluminescene and band gap engineering of $\mathrm{Mg}$ Doped $\mathrm{ZnO}$ nanoparticles, Am. J. Eng. Res. 6 (2017) 30-35.

[24] Anh-Tuan Vu, Shunbo Jiang, Keon Ho, Joong Beom Lee, Chang-Ha Lee, Mesoporous magnesium oxide and its composites: Preparation,
characterization, and removal of 2 -chloroethyl ethyl sulfide, Chem. Eng. J. 269 (2015) 82-93.

[25] Manisha C. Golcha, Vijaya S. Sangawar, Roshani N. Bhagat, Nilesh R. Thakare, Structural and morphological analysis of $\mathrm{ZnO}$ nanoparticles filled low density polyethylene thin film, Int. J. Innovat. Res. Sci. Technol. 4 (2018) 88-92.

[26] A. Geetha, R. Sakthivel, J. Mallika, Characterization of Mg doped $\mathrm{ZnO}$ nanoparticles synthesized by a novel green route using Azadirachta indica Gum and its antibacterial activity, World J. Pharm. Pharm. Sci. 6 (2017) 1189-1201.

[27] Z. Khusaimi, N.A.M. Asib, S.Z. Umbaidilah, A.N. Afaah, C.N.E. Syafika, et al.,
Synthesis and characterization of $\mathrm{MgO}$ doped $\mathrm{ZnO}$ nanorods prepared by solution immersion method and their effect on energy band gap, Int. J. Eng. Technol. 7 (2018) 186-190.

[28] J. Marselie, V. Fauzia, I. Sugihartono, The effect of $\mathrm{Cu}$ dopant on morphological, structural and optical properties of $\mathrm{ZnO}$ nanorods grown on indium tin oxide substrate, IOP Conf. Series: J. Phys. Conf. Series 817 (2017) 012014:1-6.

[29] X. Zhang, Y. Chen, T. Guo, L. Liu, M. Wei, et al., Zn-catalysed growth and optical properties of modulated ZnO hierarchical nanostructures, J. Exp. Nanosci. 7 (2012) 513-519.

[30] E. Burstein, Anomalous optical absorption limit in InSb, Phys. Rev. 93 (1954) 632-633.

[31] M. Amin, N. Abbas Shah, A. Saleem Bhatti, M. Azad Malik, Effects of Mg doping on optical and $\mathrm{CO}$ gas sensing properties of sensitive $\mathrm{ZnO}$ nanobelts, Cryst. Eng. Comm. 16 (2014) 6080-6088. 